This is the accepted manuscript of the article, which has been published in Somatechnics 2019, vol 9, no 2-3, 353-375.

https://doi.org/10.3366/soma.2019.0288

\title{
Becoming Fully Present in Your Body: Analysing Mindfulness as an
}

\section{Affective Investment in Tech Culture}

\author{
Jaana Parviainen \& Ilmari Kortelainen
}

Somatechnics 9.2-3 (2019): 353-375

DOI: $10.3366 /$ soma.2019.0288

\begin{abstract}
Tech companies have eagerly utilised mindfulness techniques in order to increase both creativity and productivity among their managers and employees. However, while a growing number of studies within fields of clinical psychology and psychiatry suggest that mindfulness provides myriad health benefits, such literature does not critically evaluate the societal and affective influences of mindfulness and other wellness practices on working bodies. By focusing on discourses related to mindfulness training, this paper explores the conception of 'being present'. Drawing on the phenomenology of the body, affect theory, and critical mindfulness studies, we develop a new theoretical framework for analysing mindfulness as a somatic and social force in technology-driven business contexts. Using research material drawn from the online advertising of mindfulness programmes for managers, this paper describes 'presence' as a new labour concept associated with the cultivated performance skill of the managerial body in the era of late capitalism. We conclude that mindfulness training - transforming the somatic into an affective investment - has transformed Buddhist meditation into capital that can be bought and consumed.
\end{abstract}

Keywords: Mindfulness, embodiment, professional training, phenomenology, affect, managerial body 


\section{Introduction}

Over the last decade, mindfulness practices have gained amazing levels of popularity in Northern America and Europe. New books on mindfulness-based interventions (MBIs) are constantly being published and, seemingly, all new health and well-being products include the word mindfulness in their titles. Interest in mindfulness has grown during times of socio-economic and technological change under post-industrial capitalism. North American companies with global reach such as Apple, Accenture, Google, HBO, Facebook, IBM, General Mills, Nike and Yahoo! are all known to have introduced meditation into the workplace, thereby emphasising awareness, presence, and mindfulness in the context of work. For instance, through the 'Search Inside Yourself' programme implemented at Google in 2007, 500 employees learned how to breathe mindfully as well as how to listen to their co-workers (Search Inside Yourself [SIY] 2018). Google also provides meditation spaces and regularly offers meditation courses to staff. Similarly, meditation has long been promoted at Apple. Seeking to pass on his passion for meditation to people in the workplace, Steve Jobs allowed employees to take 30 minutes each day to meditate at work (Seeger 2016). He also ensured that Apple provides classes on meditation and on-site yoga, in addition to providing employees with a meditation room (Garvey 2018).

Inspired by Eastern Buddhist meditation traditions such as Vipassanā tradition, mindfulness is generally understood as a process of self-improvement intended to cultivate the mind's cognitive and mental capacity through bodily practices, such as breathing techniques. According to the Theravada Buddhist tradition, the concept of mindfulness (which is known as sati in the Pali Canon of Theravada Buddhism) refers to one aspect of a broader ethically sensitive practice and way of being. Sati's original meaning was 'to remember' and 'to bear in mind', and it referred to the maintaining awareness of reality, so that the true nature of phenomenon can be seen (Stanley 2013). In contemporary medicine and cognitive psychological research on Buddhist meditation, 
mindfulness has been defined as 'paying attention in a particular way: on purpose, in the present moment, and non-judgmentally' (Kabat-Zinn 1994: 4), 'bringing one's complete attention to the present experience on a moment-to-moment basis' (Marlatt and Kristeller 1999: 68), and as an individual's propensity to be 'attentive to and aware of what is taking place in the present' (Brown and Ryan 2003: 822). These statements indicate how 'being mindfully present' represents one of the key concepts within the mindfulness discourse.

In recent years, critical studies on mindfulness have suggested that a consumerist economy exploiting the state of being mindful has emphasised the self-help aspects of mindfulness (StanleyKortelainen 2019). Dubbed 'McMindfulness', this work investigates MBIs as the marketisation of therapy culture (Madsen 2015; Purser 2019; Purser and Loy 2013; Purser et al. 2016). Kevin Healey (2015: 84) argues that corporate mindfulness programs enlighten employees within 'integrity bubbles' where a personal experience of peacefulness belies the disruption that corporate initiatives precipitate in the broader digital economy. Critics see commercial forms of mindfulness as a new emotional labour required from corporate capitalist culture and medicalisation. Kristin Barker (2014: 175), for example, argues that mindfulness practices are tied to the 'do-it-yourself' medicalisation. As self-healing and self-construction practices the purpose of the MBIs are to transform oneself into an 'authentic' being. However, the MBIs included within professional training schemes are not politically neutral and promote their own worldviews and modes of life (Barker 2014; Cook 2016; Purser and Milillo 2015; Ferguson 2016). Michel Foucault (1978) asserted that this type of disciplinary power operates on individual bodies with individual subjects regulating themselves through self-disciplinary practices which they each encouraged to adopt 'freely'. When these disciplinary practices are connected to the health and wellbeing of a population, Foucault (1978) describes these macro operations of power as biopower to refer to the ways in which power manifests itself in the fostering of life and lifestyle practices considered most productive for the economy. In this way, MBIs connect the macro processes of biopower established through social 
relationships engendered in the workplace regarding health and what is considered beneficial for increasing the productivity of the workplace as a whole and the disciplinary incitements to self-care embedded in a network of practices, institutions, and technologies operating at the micro-levels of everyday life.

Recent ethnographic and discourse analytic research from within psychological studies of mindfulness has focused attention on the embodied-discursive ways in which mindfulness teachers and students practically constitute and construct meanings of mindfulness in practice (Drage 2018; Stanley and Longden 2016). However, even these social investigations of the 'mindful-body' avoid illuminating the theoretical aspects of the somatic body in the social contexts and how the somatic body is influenced and moulded by mindfulness interventions in global business companies. Such theorisations of the body are more or less de rigueur in feminist, queer, and post-colonial accounts of the working body. For instance, somatechnics research defines the body as 'bodily-being-in-theworld' with and through technologies (Sullivan 2012). Technologies, techniques (Mauss 1979) or 'technés' (Heidegger 1977) are not something that are added or applied to 'the body', nor are they simply neutral tools that could be used to manipulate the material world and beings without profound consequences. To illustrate this point, Merleau-Ponty (1962) gives the example of a blind man who uses a walking stick in the manner as it were an extension of his own body. He says: "Once the stick has become a familiar instrument, the world of feel-able things recedes and now begins, not at the outer skin of the hand, but at the end of the stick." $(1962,175-176)$ The term 'somatechnics', thus, highlights the inextricability of the body and techné and the disposition in which corporealities, identities and styles are modified through body techniques including mindfulness practices.

Taking a critical departure from psychological studies of mindfulness, which assume $a$ priori that mindfulness automatically represents an individualising practice of self-governance, we can rather pose the question: what kinds of social and cultural worlds are being imagined through mindfulness practices and the given representations of a mindful body (Stanley and Kortelainen 
2019)? For example the question of the gender and sexuality of mindfulness bodies is a concrete cultural theme not often discussed, or even dismissed, in current the research field on mindfulness practices from cognitive psychology. To this end, in this article we have selected the most popular mindfulness programmes, which serve as representative examples of current mindfulness discourses, that is, of how mindfulness and its benefits are advertised online for managers (HesseBiber and Griffin 2013). Focusing on the discourses of 'mindfully present' in this online material, the aim of this theoretically oriented article is to provide conceptualisation of 'labour of presence'. Our critical discussion of mindfulness suggests that mindfully present managerial bodies as change agents are expected to increase innovation and productivity in tech corporations. In this sense, mindfulness practices as 'affective investments' within interpersonal work tools can increase innovation and productivity in tech corporations.

Previously, in psychologically-oriented research, presence has been referred to as an attentional function or an inner self-observation, which is highlighted in self-report measures, such as the Mindful Attention Awareness Scale (MAAS) and neuroscientific methods. Our approach to mindfulness pays attention to the political dimensions of material and immaterial power in work contexts. Though Jeremy Carrette and Richard King's (2005) and Edwin Ng's (2014) studies have illuminated the social, political, and economic consequences of self-development in the context of corporate mindfulness they have failed to capture the role of embodiment and intercorporeality within mindfulness practices. Drawing from Maurice Merleau-Ponty's ([1945] 1962) conceptualisation of pre-personal embodiment, recent discussions of somatism (Berlant 2011), and affect theories on intercorporeality (e.g. Brennan 2004; Blackman 2012), we illustrate the manner in which managerial bodies are expected to be shaped through MBI practices to become better leaders in tech business.

The article is structured as follows: in the first section, we introduce our research material and methodology on mindfulness programs. Then, we will proceed by discussing why mindfulness has 
been considered a valuable investment in somatic capital for tech companies. In the third section, we will concentrate on professional performativity to understand how self-discipline through somatism are seen as key elements of subjecting others to power in a post-industrial economy. In line with Foucault's critique, mindfulness does not represent a model of power which 'controls' or 'oppress' but a form of self-disciplinary power to which people subject themselves freely. Then, analysing the discourses of mindfulness programs, we will outline the application of concepts - prepersonality, spatial affects, and intercorporeality - to an investigation to the body politics of this discourse. Finally, we will concretise our key conceptualisation - labour of presence - by discussing the role of managerial bodies as 'change agents' in the way that their presence resonates throughout the entire organisation.

\section{Methodology and Research Material}

In order to contextualise mindfulness practices in a business context, our illustrative research consists of textual, video, and pictorial material obtained from the websites of companies and organisations that offer mindfulness programmes for the information and media technology-related industries. To describe mindfulness practices and their societal implications in work contexts, an ethnomethodological approach or, more specifically, a netnographic approach is applied in this study. A modification of the term ethnography, netnography refers to online fieldwork, following on from the conception of ethnography as an adaptable method (Kozinets 2010).

We are aware that the netnography approach lacks direct physical contact with the everyday practices of mindfulness, which means that there is a certain degree of distance from the bodies and embodied mindfulness practices. For example, Google's SIY programme is considered to be a global programme in which aspects of emotional labour, such as 'emotional intelligence', are emphasised. The SYI programme in particular, as well as other similar programmes, reflect the broader tendencies of selling embodied practices, thereby influencing individuals' visceral everyday experiences. During 
the course of such programmes, the mindfulness trainer instructs managers to learn how to lead their employees by adopting an emotionally intelligent orientation. The skill-related requirements for 'being present' typically include embracing values and stereotypical attitudes towards social and professional roles in working life. These aspects may not be immediately apparent to all those managers who would need continuous occupational mentoring to be able to handle interpersonal conflicts, work engagement, job insecurity, stress and burnouts in the workplace.

We identify relevant MBI programmes in this study based on three standards: 1) we have located websites by searching for MBI programmes that offer leadership education, since such websites reveal how MBIs are conveyed to leaders and managers in relation to the atmosphere and affect of the work environment; 2) we have sought to use a representative sample of international examples of MBIs implemented by global IT companies or MBI companies offering mindfulness programmes for IT companies; and 3) we have aimed to identify the oldest and original mindfulness programmes in order to ascertain how mindfulness training began, as well as how its rhetoric has developed. Nowadays, MBIs can be implemented in the form of mobile-phone apps, Internet-based mindfulness courses, social media, and even mindfulness-oriented games and measurement devices aimed at controlling stress levels (BrainBot 2018; Smiling Mind 2018; Zensorium 2018).

We interpreted the obtained Internet research material by applying phenomenological concepts that enabled us to explore how managerial bodies are expected to be shaped through MBI practices so as to render managers better leaders (Coole 2007). Phenomenology offers a potentially useful conceptualisation for understanding the internal experiences related to mindfulness practices, although they need to be contextualised by drawing on material derived from mindfulness as a socially lived phenomenon (Lynn and Mensinga 2015). In order to interpret the rhetoric of the mindfulness programmes advertised for managers, we analysed the interpersonal dimensions of mindfulness practices as they are manifested in mindfulness discourse, which are expected to serve as a transformative social and somatic force within teamwork. Since our research data also include 
video material, we were able to analyse details of mindfulness practices performed in social contexts in promotional media. Most videos are conveying a promotional and therefore performative message.

Managerial programmes and workshops are intended for people in leadership positions from all areas of the business world, for example, directors, business managers, technical managers, and general managers. Such programmes are often offered to groups of 15-20 people, as one-on-one training sessions or, as in the case of IBM's 'Smiling Minds Program', as training that can be tailored according to the relevant mindfulness app (Smiling Mind 2018). In addition to these websites, the research material encompasses print media texts from mindfulness-related books and popular guidebooks to mindfulness (e.g. Carroll 2007; Kaplan 2010; Chaskalson 2011; McKenzie 2013).

\section{The Affective Investment of Tech Companies in Mindfulness}

The marriage between tech giants and meditation practices, developed in the San Francisco Bay Area, is tightly rooted in the counterculture of personal liberation in Silicon Valley. The counterculture of the 1960s with marches against the Vietnam War and the meditation tools of personal liberation was appropriated away from political actions and mobilised by tech personnel toward the technoutopianism of Silicon Valley with the inventions of personal computers and later the Internet (Turner 2005, 2010). Theodore Roszak (1986) identified a dialectic that was central to the development of high tech in the Bay Area: the tension between the Reversionaries ('hippies') and the Technophiles who were identified as philosophically inclined engineers, designers, and tinkerers. Since the 1990s the Silicon Valley ethos has been manifested as a combination of libertarian, free-market ideology, and techno-bohemianism in which people were expected to compete through hard cognitive work and technological know-how in order to adapt to an atomised and accelerated sphere of start-up culture. In this version of the Californian Ideology, each member of the Silicon Valley community is promised the opportunity to become a successful hi-tech entrepreneur. Following Richard Barbrook and Andy Cameron's (1995) analysis, Joseph Del Pesco and Christian Nagler (2012) state that key elements of 
the West Coast lifestyle come from its long tradition of cultural bohemianism including experimental arts, meditation, psychedelic drugs, new age spiritualism, surfing, lesbian and gay liberation, health food, and pop music. Drawing on the cultural perceptions of radical change and free-thinking encouraged by certain communities in this area, the tech culture of Silicon Valley has established cultural capital through embracing the mindfulness boom and positioning itself as globally inclusive. 1

At the turn of the 2010s, the corporate discourse of 'living spiritually with organic forms of technology' has been aptly described by John Williams (2011: 20) as a 'technê-Zen' element that has become part of the mainstream business world. Many tech companies provide mindfulness programmes for their managers and employees, since mindfulness training is associated with the benefits of higher cognitive performance and improved resilience at work (Moore and Malinowski 2009). While it is not possible to remain in a mindful state at all times, it is recommended within this literature that people take a break for daily meditation of least 5 to 10 minutes. Due to the widespread recognition of the business potential of short-term mindfulness interventions involving mobile apps and podcasts, meditation has become a top priority in the high-tech industry.

As outlined earlier, the roots of mindfulness are often suggested to lie in Buddhist spiritual practices and the reliability of mindfulness training can now be examined by means of technologically oriented metrics, for example, magnetic resonance imaging (MRI) and electroencephalogram (EEG) brain scanning and measurements of stress levels (BrainBot 2018; Zensorium 2015). Through quantifying the effects of mindfulness, neuroscience laboratories worldwide have investigated how mindfulness meditation can modify individuals' brain activity. For instance, some studies have shown that mindfulness training can have a notable impact on the limbic system due to changing the size of the amygdala (e.g. Desbordes et al. 2012). As mindfulness practices are associated with decreased

1 Since 2012 the City of San Francisco is undergoing a technology-driven wave of growth, fueling class-divided gentrification with the consequence that traditional LGBT institutions are rapidly disappearing (Bowles \& Levin 2016; Stehlin 2015). When the city's tax incentive aimed at attracting tech companies to San Francisco over Silicon Valley the city's housing prices have climbed so high that housing costs are pushing low-income people to move from their neighborhoods. 
symptoms of stress and improved emotional regulation, it is not surprising that the business world has been eager to utilise mindfulness techniques that might improve the well-being, work engagement, team work, and productivity of workers and managers alike (Brazer et al. 2014; Dane and Brummel 2014).

'Somatism' as the core of the affective potential of mindfulness has been commodified thoroughly in the corporate mindfulness programmes analysed in this article. Instead of relying on physiological and biochemical explanation models, Lauren Berlant's (2011) conceptualisation of somatism captures embodied experience of meditation. Berlant's (2011:39) notion of somatism refers to an 'impact lived on the body before anything is understood', that is, something intuitively meaningful and ineloquent, which is felt throughout the whole body. During mindfulness training, the affective potential of the somatic is exploited to generate economic success. The demand for a 'fit mind' or the training of the 'attention muscle' is repeated in the majority of leadership programmes (Mindful Leadership Forum [MLF] 2018:

\footnotetext{
Just as we understand that there are innate capacities of our bodies that can be trained to make us more resilient, flexible and stronger, we now know from neuroscience research that there is universal training we can experience that can cultivate and strengthen our mind's capacity. Mindful Leadership training is fitness for the mind. (Marturano 2018)
}

This quote from the website of a mindfulness programme exemplifies the repeated analogy behind fitness training and mindfulness or, in a way, how mindfulness is described as 'fitness for the mind'. Mindfulness discourses seem to rely on a highly dualistic approach to embodiment, emphasising the role of the mind in managerial capabilities. However, the capacity of the manager's mind should also influence the moods and affects of his/her staff if their productivity and innovation are to be increased. 
Drawing on Lawrence Grossberg's (1992: 86) term 'affective investments', the mindfulness training of managers can be seen as the affective investment of tech companies in improving their managers' interactive skills so as to develop cohesive teamwork based on somatic potentials. While diversity and heterogeneity are found to improve decision-making and problem-solving processes through higher creativity and innovation potential (Shempla et al. 2016), a lack of cohesion within a team-working environment causes stress, tension, and conflicts. Grossberg (1992: 105) maintains that 'affect has a real power over difference, a power to invest difference and to make certain differences matter in certain ways'. In this statement, Grossberg refers to affect as a new type of discipline through which managerial bodies moderate culturally diverse work teams. We suggest that the distinctive feature of mindfulness is not mental power, as described by many within the mindfulness discourse concentrating on a 'fit mind' (MLF 2015), but 'somatic power' to build cohesion in a diverse workplace.

\section{Professional Performativity and Bodywork}

Managerial work in tech industries is assimilated into immaterial labour (Lazzarato 1996) in which interactions, relationships, networks, social capital, emotions, and communication have become central. Arlie Hochschild's (1983) conception of 'emotional labour' captures the ways workers are expected to regulate their emotions during interactions with customers, co-workers, and superiors. Although the managerial work of interpersonal relations is not regarded as a typical form of emotional labour, managers are expected to actuate the emotional processes of their employees. It is important to underline that emotional and immaterial labour is inherently material: managers regulate emotions and accomplish their work task through and in their bodies (Ladkin 2008, 2013; Sinclair 2005). When corporates want to increase their profits they put more pressure on managers' interactive capabilities to boost the productivity of their workers. Melissa Gregg (2018) shows in her study on time management in the knowledge economy how a focus on productivity isolates 
workers from one another and erases their collective efforts to define work limits and the possibilities to defend their own rights to emotional self-management.

Managers gain legitimacy in the eyes of those external to them, such as employees, stakeholders and clients, not only through claims of competence and education but through their 'professional performativity'. Tech companies, in which senior positions are dominated by men are usually masculine environments, designed by and for men (Stack Overflow 2017; Vassallo et al. 2017). Professional performativity is formed in a complex manner but it is never a simple matter of personal choice or based on education but closely connected to the physical features of gendered body. According to many feminist studies (Acker 1990; Ladkin 2013; Sinclair 2005) on work organisations, a white heterosexual embodiment has been seen a core component of corporate leadership. Sinclair (2005) argues that stature, gestures, and voice are central to constructions of authority with the consequence that the masculine male body can differentiate oneself as a winner - supremely focused, self-disciplined, and beyond physical weakness or limitation. Mindfulness discourse seems to be an attempt to dilute the hard masculinity of traditional professional performativity by encouraging male leaders to become attuned to their emotions and the emotional labour of their workers. The skills of emotional labour often viewed as innate to women have now been directed upwards to male leaders, with the potential that these kinds of roles for women at the lower end of the worker scale in interpersonal customer relations can be eliminated.

When embodying a managerial role, the central dimensions in the professional performativity of this role are temporality and spatiality closely connected with the effect of repetition (Hodgson 2005). This includes a reflexive model of authority in which actions are seen as always re-enacting previous performances in order to establish a certain effect. In Judith Butler's (1998) formulation, performativity is not simply a one-time condition or static state, but rather, it is seen as temporalised, as a continual and circular process of sedimentation and congealment. Professional performativity, in this sense, must be understood not as a singular or deliberate act, but as a reiterative practice. From 
this perspective, the position of male authority achieved through daily acts involves a far more complex process than simply learning to enact a stereotyped leadership role.

Reflexive awareness and self-discipline are seen as key elements of the control achieved through managerial position in a post-industrial economy (Shilling 2004). In order to present a convincing impression of themselves to clients, employees, and superiors, leaders typically feel pressured to undertake bodywork (Gimlin 2002, 2007; Waring 2008; Coffey 2013) which starts with make-up and power dressing ranging from a personal's trainer's fitness program and diets to cosmetic surgery, mood stabilizers, and microdosing. In their study on academic work cultures, Sue Saltmarsh and Holly Randell-Moon (2014) consider how the obligation or 'duty to happiness' is constructed through academic performativities, implicated in discursive fictions that equate work-life balance with personal and organisational well-being. The rise of mindfulness during the 2010s has highlighted the need for novel managerial interventions that utilise body techniques to get involved in a deeper level of psychosomatic competency to modify human interactive capabilities.

To elaborate further Berlant's (2011: 39) notion of the somatic, we develop our key conceptualisation of embodied agency, providing for a phenomenological account of mindfulness practices. Therefore, we turn to Merleau-Ponty's ([1945] 1962) conceptual distinction between the personal and pre-personal aspects of embodiment to understand the somatic purchase of mindfulness discourse. We assume that mindfulness techniques attempt to gain access to the 'pre-personal' level, instead of the lived body as Berlant (2011: 39) suggests. For Merleau-Ponty ([1945] 1962), the lived body is constituted by our conscious experience of the body and the world, while the pre-personal refers to 'another subject' beneath personal behaviour. Accordingly:

My personal existence must be the resumption of a pre-personal tradition. There is, therefore, another subject beneath me, for whom a world exists before I am here, and who marks out my place in it. This captive or natural spirit is my body, not that momentary body which is the instrument of my personal choices and which fastens upon this or that world, but the system of anonymous 'functions' which draw every particular focus into a general project. (Merleau-Ponty [1945] 1962: 254) 
For Merleau-Ponty, this anonymous existence appears before the reflexive awareness of the live body including the most vital and founding experiences from the early childhood. Mindfulness as bodywork thus refers to the self-disciplines thought which one gets contact with the pre-personal level to improve managerial activity. This indicates that there is a distinction posited between the working body as a conscious, rational, and choice-driven one compared to a prior essence that has not been commodified. This is exemplified in MBI training through such expressions as 'releasing muscular tension', 'fostering the body', and 'acting with awareness', as well as through the more general aspects of health, well-being, and self-care that include embodied aspects (Body-MindEmotions Awareness Lab [BEAL] 2018; The Potential Project [PP] 2018). A more complex situation is often referred to in the case of 'non-reactivity to inner experience', since it does not explicitly manifest bodily movement, although it remains an important aspect of affective embodiment during mindfulness training.

The benefits of mindfulness techniques differ from the traditional performative skills that aim at communicating with other people through exact gestures, postures, facial expressions, tones of voice, and power dressing. Mindfulness websites repeat the quality of 'self-leadership' and underline the key discipline for streaming the qualities of 'presence and self-mastery that are most essential to personal sustainability and success' (MLF 2018).

\section{Affect and Intercorporeality}

During past two decades, the discussion of emotions in the social theory (e.g. Ahmed 2004; Brennan 2004; Wetherell 2012) focused on conceptualisations of 'affect' as an intersubjective phenomenon in society. 'Affect' can broadly be defined as subjective, inter-corporeal, and at least partly socially adopted corporeal feelings and sensations (cf. Blackman and Venn 2010). For Theresa Brennan (2004), affects are regarded as resulting from the circular interaction between affective affordances in the environment and the subject's bodily resonance. Affects do not reside in subjects or objects, 
but are instead produced in circulation between bodies (Ahmed 2004). During this circulation, affects are not fixed and organised processes, since they are the effects of social dynamics - they are susceptible to being changed and transformed. The circulations of affects are frequently intertwined with power structures and social hierarchies with the consequence that 'emotional infrastructures' or 'affective atmospheres' may reinforce normative or patriarchal values.

While 'affect' is understood as an inherently intersubjective phenomenon, it is tightly bound up with intercorporeality. In using the term intercorporeality, we return to phenomenological conceptualisations to deconstruct the concept in relation to the pre-personal bodies (Merleau-Ponty 1964; Weiss 1999). Gail Weiss (1999: 5) describes intercorporeality by stating that 'the experience of being embodied is never a private affair, but is always already mediated by our continual interactions with other human and nonhuman bodies'. Instead of merely reading body language, signs, and gestures, people have tendency to follow rhythms and spatial directions of the gestures by responding to these rhythms, atmospheres, and spatial transition with their own bodily movements (Coole 2007). In this sense, pre-personal bodies are constantly being exposed to intercorporeal rhythms and atmospheres, sometimes synchronising their bodily movements with them and sometimes finding themselves to be 'dissonant bodies', causing or being received as causing friction and tensions in their environment. Using Kathleen Stewart's (2011) formulation of atmospheric attunements, atmospheres can pull individual bodies' senses into alert or incite distraction or denial. Although bodies are immersed in atmospheres that affect their mood, most people find it difficult to describe the precise character of a certain atmosphere or to explain exactly how it affected them.

In the contexts of managerial bodies, mindfulness training is expected to improve interpersonal capabilities, including emotional intelligence skills with handling affective atmospheres at workplaces. Using here the phenomenological conceptualisation, the mindfulness programmes implemented by the most successful and influential technology companies - such as IBM's Smiling Mind or Google's SIY programme - aim at facilitating an individual's affective capacities, which are 
pre-personal, 'under' emotions. For instance, Google's SIY programme refers to 'inner capacities'. Manipulating one's own inner capacities is a means of personal liberation, yet, under strict company guidance.

SIY uses the practices of mindfulness to train Emotional Intelligence skills, leading to resilience, positive mindset, and centered leadership. In the midst of complexity, it's about finding the inner capacity to create, to thrive, to lead. And it's surprisingly fun. (SIY 2018)

Liberating the inner capacity of managerial bodies (so they can more effectively lead) can be associated with the tech giant's relentless drive to diversify and intensify the creative powers of human labour towards a transformation of an individual's own most intimate moods, experience, imagination, and sensations in the working lifespans as the fuel of capitalism. Working within tech culture, this leads managers to a contradictory situation. On the one hand, managerial bodies cannot challenge the programmes of 'positive mindset' since the purpose of these techniques is to enhance their wellbeing and productivity. On the other hand, the mindfulness programmes attempt to encroach on their individual autonomy. Mindfulness practices attempt to grasp the pre-personal corporeality and intersubjective capacity in order to transform not just managerial bodies but their subordinates' affective states. Therefore, the dynamism of the pre-personal includes 'affective incitement' (Behnke 2008), which means that employees are to be affected by their manager's behaviour, as well as through the atmospheres of the work environment.

'Becoming a mindful leader' is generally discussed vicariously in connection with psychological qualities, such as becoming 'resilient, flexible and stronger'. However, these qualities are not only related to the mind's capacity since they are also aimed at influencing the moods and affects of the workplaces. Our suggestion is that managers are not only expected to improve their individual psycho-somatic effectiveness, but also to foster new levels of creativity by establishing inspiring workspaces and affective atmospheres. New forms of work and self-discipline are linked 
to the 'somatic potentials' of managerial bodies in terms of the ways in which they can induce a state of enthusiasm at work motivating people to exceed their limits.

\section{Presence of Labour and Affective Atmospheres}

As a leader, you have come to realize that in today's creative economy it takes more than the latest skills and hard work to sustain stellar performance in an age where complexity and unknowns rule the day. / Sustainable success is now based on radically innovative thinking combined with the will to act with emotional maturity towards a meaningful purpose - embodied by the entire organization. (Integral Business Leadership Group [BLG] 2018)

The above quotation suggests that, through mindfulness training, managerial bodies as 'change agents' do not just improve their internal innovative thinking, but also develop their style of leading so that it resonates throughout the entire organisation. By practicing spiritual exercises, such as yoga and meditation, managers should be capable of spreading their own habitual patterns of feeling over the whole organisation (BEAL 2018). Mindfulness programmes, such as 'Business Integral', include learning to develop 'a stronger leadership presence' (BLG 2018). We identify this willpower of leadership as 'presence of labour' which aims at capturing a special kind of embodied state that can be accessed through mindfulness techniques.

Presence of labour refers to the 'non-action' or 'non-doing' that, in the mindfulness rhetoric, involves refraining from acting but not in the sense of being passive or resting. By keeping attention in the present moment, instead of thinking about the past or the future, non-action as forbearance and patience takes sustained effort and labour. Being engaged in the non-action state, managerial bodies learn to not being preoccupied with expectations and goals. They learn to resist impulses and refrain concerns with their self-identity and self-aversion in favour of experiencing a peaceful state with the capacity for reactivity and calmness, spontaneity, and discipline. In holding back 'negative moods' like suffering, stress, and distress, the effect of this demanding self-practice is concretised in the 
intensified bodily presence of managerial bodies that emanate energy within the work organisation.

Google's 'Search Inside Yourself' webpage includes a video called 'Introduction to Emotional Intelligence'. In this video, self-discipline is presented in a very detailed manner as something that can be trained through bodily mindfulness practices. For example, achieving detachment from anger in the moment it arises is possible when the anger is recognised within the body. In response to anger, a mediating subject is described as breathing differently because of a feeling, or experiencing chest tightening, and so on (SIY 2018). This self-confident yet sensitive 'guru' attitude is supposed to radiate from the managerial body, thereby assuring employees and clients alike that this guru can easily and successfully execute the most utopian ideas and plans. The Mindful Leadership Forum (2018) formulates this by saying, 'Mindful Leadership is about fully accepting yourself and bringing your whole self to work. You don't have to act like someone else. You "walk the talk", and people experience "you as honest, transparent and real"'. Within mindfulness practices, managerial bodies enable these actors to live rather than to display their professional roles. To convince clients and employees, they aim to create the proper affective atmosphere necessary to facilitate successful work performance.

Turning back to the discussion of spatial and temporal dimensions of professional performativity, the workplaces of tech companies resemble stages or scenes in theatre rather than sterile offices or workrooms (Thrift 2000). As designed sceneries, the workplaces of tech companies tighten embodied work performances, forcing some people out, while intensifying the group cohesion of other people who share common identities, feelings, and beliefs. Instead of division between the actors and the audience, all workers and managers at the stage both monitor and are being measured by the others. This tight embodied system develops affective atmospheres, meaning that people may feel something 'in the air' by sensing an interpersonal climate, for example, a serene, solemn, or threatening atmosphere (Fuchs 2013: 613). The affective atmospheres are experienced through a resonance of the body, for instance, an icy atmosphere feels chilly, an uncanny situation makes 'one's 
hair stand on end', and a tense interpersonal climate is felt to be oppressive or suffocating (Fuchs 2013: 616).

Google's SIY programme advancing managerial bodies' emotional intelligence refers to the need to exploit the potential of spatiality that can stimulate people's creativity in product and service development in the tech industry. The interiors and sceneries of tech companies are designed to emanate distinct atmospheres for different work performances, for instance, by offering space for employees calming down in meditation rooms or intensifying shared feelings with colleagues in colourful playrooms. Affective spaces within technology companies include atmospheres with digital devices, a futuristic design (such as Google Campuses), and new office solutions, which urge bodies to engage in innovative interpersonal communication (See Peteri 2017, 8). Managerial bodies as change agents should be able to develop a co-creation that is beneficial for innovative work. In order to enhance team spirit and increase creativity among employees, managers and leaders are expected to foster affective spaces for successful negotiations with clients or to inspire employees to increase their work performance.

Relying on mindfulness practices, managerial bodies work as 'catalysers' between chief executives and workers to execute the company's strategy. When the Mindful Leadership Global Forum (2018) urges managers to foster 'the development of compassion and deepen your relationship with others', the corporate culture has reasons to soften its combination of calculated and determined self-restraint by the rhetoric of compassion. Office designs with abstract art on the walls and ambient music as favourable climates for innovation are calculated by tuning bodies so that they become more efficient and productive. Despite the apparent emphasis on teamwork, the work performances of individual workers are evaluated by Excel matrixes. All aspects within a given corporation, even the most inspiring, can be replaced and reorganised: workers, teams, the material resources, the infrastructure, and the activities engaged in, including the affective spaces of a new kind of atmosphere. 
When managerial bodies try to improve managerial activity through potentials of the somatic, the requirements of presence and authenticity raise questions about whether they are capable of distancing themselves from their professional roles. Are these managerial actors, after all, swallowed up in their roles in such a way that their professional roles have now become their other skins and new identities as Saltmarsh and Randell-Moon (2014) suggest in their study of academic employees? Affective investments in 'being present' can lead to professional performativity in such a way that the pre-personal level of human existence is occupied by corporations, since mindfulness training is itself motivated by economic survival. Indeed, investments in mindfulness and authenticity training may herald a new phase of 'caring imperialism' that does not allow resistance or disagreeable emotions. Furthermore, a worker whose embodiment or professional style does not fit with the ideals of a mindful workplace can distort and create unpredictable cracks in the affective atmospheres and shared feelings created by his/her leader (see Saltmarsh \& Randell-Moon 2014).

Moreover, one of the crucial outstanding questions concerns whether mindfulness training can actually make it more difficult for people to resist organisational malpractices, deflect abuse, and refuse to engage in overwork (e.g. Hodson 1995; Rader 2008; Pullen and Rhodes 2015). When mindfulness practices work on the pre-personal level, developing a non-judgmental attitude and cognitive flexibility can make it difficult for people to raise issues related to labour processes that adversely impact their working conditions. When people are required to be more present and to pay greater attention to their co-workers' feelings, it becomes difficult to resist managerial interventions that might narrow their own autonomy at work. Employees may try to avoid conflicts with their managers and colleagues, since such conflicts are negatively associated with job satisfaction and, potentially, stigmatise employees as 'trouble makers' within the organisation (see Saltmarsh and Randell-Moon 2014).

More empirical research is needed to examine how mindfulness manifests within the practical and political acts of organisational cultures. Relevant research questions include: do mindfulness 
practices actually support dominant organisational power relations including the dominance of white male heterosexuality? Can the use of mindfulness practice regress the developmental processes of gender equality within organisations? It is important to study further how mindfulness interventions in tech industries are meant to dilute criticisms of the traditional macho business culture as uncaring and unconcerned with equality. In order to further analyse mindfulness interventions from the perspective of workers, new empirical research data needs to be collected concerning the somatic consequences of mindfulness practices on the work cultures of high-tech industry.

\section{Conclusions}

In the present article, we have examined the discourse of mindful management by developing a broader understanding of mindfulness practices as an affective investment in tech culture contexts. We reviewed various mindfulness-driven coaching programmes designed for managers and leaders in order to understand how pre-personal potentials are used to develop presence of labour in managerial work. Drawing on both the phenomenology of the body and affect theories, we discussed mindfulness in relation to the increasing pressure to be innovative and creative in tech businesses. We suggest that mindfulness is traditionally considered to be antithetical to performativity, since it is the search for an authentic way of being that involves focusing one's complete attention on the present experience and unlearning habitual ways of responding to everyday situations. However, in the context of the mindfulness programmes analysed here, mindfulness is mobilised as part of leader performativity through incitements to model an affective attunement to the emotions and atmospheres of the workplace and workers. The use of 'soft' mindfulness practices does not necessary dismantle the hard masculinity of high-tech companies since guru attitudes and calculated compassion are meant to assure employees that they can execute the most utopian ideas and plans.

Mindfulness training and practices appropriating Buddhist traditions and as instituted within corporations, capitalise on the facilitation of proper positive affect and bodily moods in order to build 
styles of performativity and a certain kind of social cohesion in the workplace. Mindfulness techniques have been sold to hold great potential for managers in terms of how they can develop their performativity as ethically and globally responsive leaders (Stanley 2013: 632). 'Body-mind' techniques are portraying as having profound effects on a pre-personal level, described as they were therapeutic sessions. Hence, they apply powerful embodied content in their commodification actions.

By analysing the webpages and self-help literature, we found diverse motives for the coupling of mindfulness training with high-tech companies. Mindfulness encompasses mood displays and affective spaces wrapped up in an ambivalent rhetoric that simultaneously suggests 'productivity' and 'no gain'. That is, mindfulness is encouraged as a beneficial psychosomatic end in itself despite being promoted as evidently linked to increased productivity and creativity. Somatic training, as well as a meditative lifestyle, are melded in an effort to achieve economic success. Yet, the discourse of mindfulness represents neutrality, emphasising health and well-being and therefore avoids embarrassing and structural questions of class, race/ethnicity, and gender inequalities that also attend to some bodies in the workplace.

We do not deny the possibility that mindfulness does produce certain well-being benefits for managerial bodies at their demanding and stressful work. However, we suggest that the research mobilised in support of mindfulness training programmes and practices does not discuss the political dimensions of this type of affective investment of tech companies since most requirements for embodiment are tacit and unspoken. This article suggests that the mode of presence of labour through mindfulness practices does not only concern internal cognitive and mental capacities. The use of mindfulness practices attempts to grasp the pre-personal corporeality of managerial bodies in order that the creative potentials of work teams can be generated more successfully under the strong guidance of visionary gurus. 


\section{References}

Acker, Joan (1990), 'Hierarchies, jobs, bodies: A theory of gendered organizations', Gender \& Society, 4: 2, 139-158.

Ahmed, Sarah (2004), Cultural Politics of Emotion, London: Routledge.

Barbrook, Richard and Andy Cameron (1995), 'The Californian Ideology', Mute 1: 3. Available at http://www.imaginaryfutures.net/2007/04/17/the-californian-ideology-2/[Accessed 3.04.2019].

Barker, Kristin (2014), 'Mindfulness meditation: Do-it-yourself medicalization of every moment', Social Science and Medicine, 106, 168-176.

Behnke, Elizabeth A. (2008), 'Interkinaesthetic affectivity: A phenomenological approach', Continental Philosophy Review, 41: 2, 143-161.

Berlant, Lauren (2011), Cruel Optimism, Durham: Duke University Press.

Blackman, Lisa (2012), Immaterial Bodies, Los Angeles: Sage.

Blackman, Lisa and Couze Venn (2010), 'Affect', Body and Society, 16: 1, 7-28.

Body-Mind-Emotions Awareness Lab [BEAL] (2018), 'Method'. Available at http://cultivatingselfleadership.com/seminarstrainings/bodyemotions-awareness-lab/ [Accessed 23.10.2018].

Bowles, Nellie and Sam Levin (2016), San Francisco's tech bros told: Quit changing the gayborhood. 2.2.2016 The Guardian. Available at https://www.theguardian.com/world/2016/feb/02/san-francisco-gay-bars-shut-down-lgbttenderloin-castro-district [Accessed 6.8.2019].

BrainBot (2018), 'Mindful Technology'. Available at http://www.brainbot.me/ [Accessed 14.10 .2018].

Brazer, S. David, Sharon D. Kruse and Sharon Conley (2014), 'Organizational theory and leadership navigation', Journal of Research on Leadership Education, 9: 3, 254-272. 
Brennan, Theresa (2004), The Transmission of Affect, Ithaca: Cornell University Press.

Brown, Kirk Warren and Richard M. Ryan (2003), 'The benefits of being present: Mindfulness and its role in psychological well-being', Journal of Personality and Social Psychology, 84: 4, 82248.

Butler, Judith (1998), The Psychic Life of Power: Theories in Subjection, Stanford: Stanford University Press.

Carrette, Jeremy and Richard King (2005), Selling Spirituality. The Silent Takeover of Religion, New York: Routledge.

Carroll, Michael (2007), The Mindful Leader: Ten Principles for Bringing out the Best in Ourselves and Others, Boston: Trumpeter Books.

Chaskalson, Michael (2011), The Mindful Workplace, Developing Resilient Individuals and Resonant Organizations with MBSR, West Sussex: Wiley-Blackwell.

Coffey, Julia (2013), ‘Bodies, body work and gender: Exploring a Deleauzian approach', Journal of Gender Studies, 22: 1, 3-16.

Cook, Joanna (2016), 'Mindful in Westminster: the politics of meditation and the limits of neoliberal critique', HAU: Journal of Ethnographic Theory, 6: 1, 141-161.

Coole, Diana (2007), 'Experiencing discourse: corporeal communicators and the embodiment of power', British Journal of Politics and International Relations, 9: 3, 413-33.

Dane, Erik and Bradley Brummel (2014), 'Examining workplace mindfulness and its relations to job performance and turnover intention', Human Relations, 67: 1, 105-128.

Del Pesco, Joseph and Nagler, Christian (2012), 'Christian Bay Area art and the (counter) culture of Silicon Valley', in Six Lines of Flight: Shifting Geographies in Contemporary Art, ed. Apsar DiQuinzio, Berkeley: University of California Press, 153-161.

Desbordes, Gaelle, Lobsang T. Negi, Thaddeus W. W. Pace, B. Alan Wallace, Charles L. Raison and Eric L. Schwartz (2012), 'Effects of mindful-attention and compassion meditation training on 
amygdala response to emotional stimuli in an ordinary, non-meditative state', Frontiers in Human Neuroscience, 6, 1-15.

Drage, Matthew (2018), 'Of mountains, lakes and essences: John Teasdale and the transmission of mindfulness', History of the Human Sciences, 31: 4, 107-130.

Ferguson, Michaele L. (2016), ‘Symposium: Mindfulness and politics: Introduction', New Political Science, 38: 2, 201-205.

Foucault, Michel (1978), The History of Sexuality Vol. 1: The Will to Knowledge (La volonté de savoir, 1976), London: Penguin.

Fuchs, Thomas (2013), 'The Phenomenology of Affectivity', in The Oxford Handbook of Philosophy and Psychiatry, eds. K. W. M. Fulford, Martin Davies, Richard G. T. Gipps, George Graham, John Z. Sadler, Giovanni Stanghellini and Tim Thornton, Oxford: Oxford University Press, 612631.

Garvey, Marianne (2018), 'Meditation rooms are the hottest new work perk', Market Watch 26.10.2018. Available at https://www.marketwatch.com/story/meditation-rooms-are-the-hottestnew-work-perk-2018-10-26 [Accessed 13.8.2019]

Gimlin, Debra (2002), Body Work: Beauty and Self-Image in American Culture, Berkeley: University of California Press.

Gimlin, Debra (2007), 'What is body work?', Sociology Compass, 1: 1, 353-370.

Gregg, Melissa (2018), Counterproductive: Time Management in the Knowledge Economy, Durham: Duke University Press.

Grossberg, Lawrence (1992), We Gotta Get out of This Place: Popular Conservatism and Postmodern Culture, London: Routledge.

Healey, Kevin (2015), 'Disrupting Wisdom 2.0: The Quest for "Mindfulness" in Silicon Valley and Beyond', Journal of Religion, Media and Digital Culture, 4: 1, 67-95. 
Heidegger, Martin (1977), The Question Concerning Technology and Other Essays. Trans. by Willlian Lovitt. New York \& London: Garland Publishing.

Hesse-Biber, Sharlene and Amy J. Griffin (2013), 'Internet-mediated technologies and mixed methods research: Problems and prospects', Journal of Mixed Methods Research, 7: 1, 43-61.

Hochschild, Arlie (1983), The Managed Heart, Berkeley, University of California Press.

Hodgson, Damin (2005), 'Putting on a professional performance: Performativity, subversion and project management', Organization, 12: 1, 51-68.

Hodson, Randy (1995), 'Worker resistance: An underdeveloped concept in the sociology of work,' Economic and Industrial Democracy, 16: 1, 79-110.

Integral Business Leadership Group [BLG] (2018), 'Corporate Mindfulness Programs'. Available at http://www.businessintegral.com/ [Accessed 3.02.2018].

Kabat-Zinn, Jon (1994), Wherever You Go, There You Are: Mindfulness Meditation in Everyday Life, New York: Hyperion.

Kaplan, Jonathan (2010), Urban Mindfulness: Cultivating Peace, Presence, and Purpose in the Middle of It All, Oakland: New Harbinger Publication.

Kozinets, Robert V. (2010), Netnography: Doing ethnographic research online, Thousand Oaks: Sage Publications.

Ladkin, Donna (2008), 'Leading beautifully: How mastery, congruence and purpose create the aesthetic of embodied leadership practice', The Leadership Quarterly, 19: 1, 31-41.

Ladkin, Donna (2013), 'From perception to flesh: A phenomenological account of the felt experience of leadership', Leadership, 9: 3, 320-334.

Lazzarato, Maurizio (1996), 'Immaterial labour', in Radical thought in Italy a potential politics, eds. Paolo Virno and Michael Hardt, Minneapolis: University of Minnesota Press, 142-157.

Lynn, Robyn and Jo Mensinga (2015), 'Social workers' narratives of integrating mindfulness into practice', Journal of Social Work Practice, 29: 3, 255-270. 
Madsen, Ole J. (2015), Optimizing the Self: Social Representations of Self-Help, London: Routledge.

Marlatt, G. Alan and Jean L. Kristeller (1999), 'Mindfulness and meditation', in Integrating Spirituality into Treatment, ed. W. R. Miller, Washington: American Psychological Association, $67-84$.

Marturano, Janice L. (2018), 'Definitions'. IML Institute for Mindful Leadership. Available at http://instituteformindfulleadership.org/ [Accessed 22.10.2018].

McKenzie, Stephen (2013), Mindfulness at Work: How to Avoid Stress, Achieve More, and Enjoy life!, New Jersey: The Career Press.

Merleau-Ponty, Maurice [1945] (1962), Phenomenology of Perception, trans. Colin Smith, New York: Routledge.

Merleau-Ponty, Maurice (1964), The Visible and the Invisible, trans. Alphonso Lingis, Evanston: Northwestern University Press.

Mindful Leadership Forum [MLF] (2018), ‘The Three Pillars of Mindful Leadership'. Available at http://mindfulleadershipforum.com/ [Accessed 6.03.2018].

Moore, Adam and Peter Malinowski (2009), 'Meditation, mindfulness and cognitive flexibility', Consciousness and Cognition, 18: 1, 176-186.

Mauss, Marcel [1935] (1979), 'Body techniques', in Sociology and Psychology: Essays by Marcel Mauss, trans. Ben Brewster, London: Routledge \& Kegan Paul, 95-123.

Ng, Edwin (2014), 'Towards a dialogue between Buddhist social theory and "affect studies" on the ethico-political significance of mindfulness', Journal of Buddhist Ethics, 21, 353-384.

Peteri, Virve (2017), 'Bad enough ergonomics: A case study of an office chair', SAGE open, 1: 7, 111.

Pullen, Alison and Carl Rhodes (2015), 'Ethics, embodiment and organizations', Organization, 22: $2,159-165$. 
Purser, Ronald (2019), McMindfulness: How Mindfulness Became the New Capitalist Spirituality. San Francisco, CA: Green Apple Books.

Purser, Ronald and David Loy (2013), 'Beyond McMindfulness', The Huffington Post. Available at http://www.huffingtonpost.com/ron-purser/beyond-mcmindfulness_b_3519289.html [Accessed 15.07.2014].

Purser, Ronald and Joseph Milillo (2015), 'Mindfulness revisited: A Buddhist-based conceptualization', Journal of Management Inquiry, 24: 1, 3-24.

Purser, Ronald, David Forbes and Adam Burke (2016), Handbook of Mindfulness: Culture, Context and Social Engagement, New York: Springer.

Rader, Victoria (2008), 'Solidarity on the job: Resisting dehumanization and fighting for democracy in the diverse workplace', Humanity \& Society, 32: 4, 387-407.

Roszak, Theodore (1986), From Satori to Silicon Valley: San Francisco and the American Counterculture, San Francisco: Don't Call It Frisco Press.

Saltmarsh, Sue and Holly Randell-Moon (2014) 'Work, life, and im/balance: Policies, practices and performativities of academic well-being', Somatechnics, 4: 2, 236-252.

Search Inside Yourself [SIY] (2018), 'Google's Search Inside Yourself Program', Public Programs. Available at http://siyli.org/publicprograms/ [Accessed 23.10.2018].

Seeger, Clara (2016), Mindfulness At Work In A Week: Learn To Be Mindful In Seven Simple Steps. London: Hachette.

Shemla, Meir, Bertol Meyer, Lindred Leura Greer and Karen A. Jehn (2016), ‘A review of perceived diversity in teams: Does how members perceive their team's composition affect team processes and outcomes?', Journal of Organizational Behavior, 37: 1, 89-106.

Shilling, Chris (2004), 'Physical capital and situated action: A new direction for corporeal sociology', British Journal of Sociology of Education, 25: 4, 473-87. 
Sinclair, Amanda (2005), 'Body and Management Pedagogy', Gender, Work and Organization 2: 1, 89-104.

Smiling Mind (2018), 'Smiling Mind: Corporate Program at IBM'. Available at https://www.google.fi/search?q=Smiling+Mind+corporate+program+at+IBM\&ie=utf-8\&oe=ut f-8\&aq=t\&rls=com.frontmotion:en-US:unofficial\&client=firefox-a\&channel=sb\&gfe_rd=cr\&e $\mathrm{i}=30 \mathrm{DRVLO}-\mathrm{Fd} 2 \mathrm{DuAG04YCADw}$ [Accessed 23.10.2018].

Stack Overflow (2017), 'Developer survey results 2017'. Available at https://insights.stackoverflow.com/survey/2017\#overview [Accessed 3.04.2019].

Stanley, Steven (2013), 'From discourse to awareness: Rhetoric, mindfulness, and a psychology without foundations', Theory \& Psychology, 23: 1, 60-80.

Stanley, Steven and Charlotte Longden (2016), 'Constructing the mindful subject: reformulating experience through affective-discursive practice in Mindfulness-Based Stress Reduction', in Handbook of Mindfulness: Culture, Context and Social Engagement, eds. Ronald F. Purser, David Forbes and Adam Burke, New York: Springer, 305-322.

Stanley, Steven and Ilmari Kortelainen (2019), 'Assembling mindful bodies: mindfulness as a universal 'laboratory of practice', in Assembling Therapeutics: Cultures, Politics and Materiality eds. Suvi Salmenniemi, Johanna Nurmi, Inna Perheentupa, Harley Bergroth (Forthcoming in August 30, 2019).

Stehlin, John (2016), The post-industrial "shop floor": Emerging forms of gentrification in San Francisco's innovation economy. Antipode, 48: 474- 493. doi: 10.1111/anti.12199.

Stewart, Kathleen (2011), 'Atmospheric attunements', Environment and Planning D: Society and Space, 29: 3, 445-453.

Sullivan, Nikki (2012), 'The somatechnics of perception and the matter of the non/human: A critical response to the new materialism', European Journal of Women's Studies, 19: 3, 299-313. 
The Potential Project [PP] (2018), 'The Corporate-Based Mindfulness Training'. Available at http://potentialproject.com/ [Accessed 23.10.2018].

Thrift, Nigel (2000), 'Performing culture in the new economy', Annals of the Association of American Geographers, 90: 4, 674-692.

Turner, Fred (2005), 'Where the counterculture met the new economy: The WELL and the origins of virtual community', Technology and Culture, 46: 3, 485-512.

Turner, Fred (2010), From Counterculture to Cyberculture: Stewart Brand, the Whole Earth Network, and the Rise of Digital Utopianism, Chicago: University of Chicago Press.

Vassallo, Trae, Ellen Levy, Michele Madansky, Hillary Mickell, Bennett Porter, Monica Leas and Julie Oberweis (2017), 'Elephant in the Valley'. Available at https://www.elephantinthevalley.com/ [Accessed 23.10.2018].

Waring, Amanda (2008), 'Health club use and "lifestyle": Exploring the boundaries between work and leisure', Leisure Studies, 27: 3, 295-309.

Weiss, Gail (1999), Body Images: Embodiment as Intercorporeality, New York: Routledge.

Wetherell, Margaret (2012), Affect and Emotion: A New Social Science Understanding, London: Sage.

Williams, John R. (2011), 'Technê-Zen and the spiritual quality of global capitalism', Critical Inquiry, 38: 1, 17-70.

Zensorium (2018), 'Being'. Available at http://www.zensorium.com/being [Accessed 23.10.2018]. 